\title{
Determinants of under-five mortality clustering in a health and demographic surveillance system in Zamfara State, northern Nigeria Olatunji Alabi ${ }^{1}$, Olugbenga A. Oyedokun ${ }^{2}$, Henry V. Doctor ${ }^{3}$ \& Sunday A. Adedini ${ }^{2,4}$
}

${ }^{1}$ Department of Demography and Social Statistics, Federal University, Birnin-Kebi, Nigeria

${ }^{2}$ Department of Demography and Social Statistics, Obafemi Awolowo University, Ile-Ife, Nigeria

${ }^{3}$ World Health Organization, Regional Office for the Eastern Mediterranean, Cairo, Egypt

${ }^{4}$ Demography and Population Studies Programme, University of the Witwatersrand, Johannesburg, South Africa yomistorii@yahoo.com

\begin{abstract}
Despite global reduction, under-5 mortality remains high in most developing countries and tends to cluster among certain individuals, households and communities. We assess levels and factors influencing under-5 mortality clustering in a rural setting in northern Nigeria. Data were collected from January 2011 to December 2013 at Nahuche Health and Demographic Surveillance System. Binomial distribution and Poisson regression model were used to assess family level clustering and factors associated with under- 5 mortality clustering. Results show that there was under- 5 mortality clustering, with $5 \%$ of the compounds accounting for $35 \%$ of all deaths. Surviving beyond infancy was associated with reduced incidence rate of under-5 mortality clustering $(p<0.05)$. Child's age, source of drinking water and type of provider at delivery during the most recent birth $(p<0.05)$ influenced under-5 mortality clustering. Findings call for evidence-based policies to reduce under-5 mortality.
\end{abstract}

Keywords: Under-5 mortality; Mortality clustering; INDEPTH Network; Nigeria

\section{Introduction}

Under-5 mortality, defined as the number of children dying between birth and the fifth birthday (0-59 months) - and usually expressed per I,000 live births (NPC and ICF International 2014) - is one of the indicators of development. Despite the 49\% reduction in global under-5 mortality rates (U5MR) since the 1990s (UNICEF 20I4), the 5.9 million under- 5 deaths in 2015 demonstrates the challenges associated with global reduction in U5MRs (You et al. 2015). Variation in under-5 deaths between the developed and developing countries was about 16fold, with the highest rate in Sub-Saharan Africa and Asia estimated at over 93 and 37 deaths per 1,000 live births respectively (UNICEF 20I4).

Child health indicators are generally poor in SubSaharan Africa, Nigeria inclusive, with 7 countries with U5MRs exceeding 100 deaths per 1,000 livebirths located in the region (You et al. 2015). Worse still, within Nigeria, U5MRs vary between regions and place of residence (Alabi and Doctor 2015): U5MRs are higher in rural areas (167 deaths per I,000 livebirths) than in urban areas (100 deaths per I,000 livebirths) and also highest in North West geo-political zone (185 deaths per I,000 livebirths) (NPC and ICF International, 20I4). Although U5MRs in Nigeria decreased from 201 deaths per I,000 live births in 2003 to 128 deaths per I,000 live births in 2013 (NPC and ICF International 20I4), the prevailing U5MRs of over 100 deaths per 1,000 live births underscore the need for renewed efforts at understanding the dynamics and drivers of high U5MRs in Nigeria in general and northern Nigeria in particular.

In Nigeria, the Federal, State, and Local governments have implemented a number of initiatives to address the persistently high U5MRs especially in the northern part of the country. Some of the efforts include the integrated maternal and child health initiative by the Federal Government aimed at revitalizing the Primary Health Care (PHC) in every Local Government Area (LGA) and setting aside selected days annually designated as 
"Immunization Plus Days" (IPDs) for the eradication of polio virus among under- 5 children. Further the routine immunization campaign for newborns and under-5 children is a regular event in Nigeria. Other efforts aimed at improving maternal and child health in Nigeria includes campaigns for the adoption of family planning methods by couples.

However, despite the investment in health promotion interventions and wealth of knowledge on the determinants of under-5 mortality, there are limited policies that underpin the critical factors sustaining the high U5MR. The available knowledge on the topic has not translated into implementable policies needed to reduce the high under-5 mortality in Nigeria. This development underscores the importance of further research to understand the complex mechanism surrounding under-5 mortality. One under-researched area in developing countries in general and Nigeria in particular is the study on under-5 mortality clustering. Understanding the determinants of under-5 mortality clustering is of great interest to researchers in the field (Alabi et al. 2015).

Considering that child deaths tend to concentrate in some families and among few women, understanding the characteristics of families or women with the highest burden of under-5 mortality and the causes of under- 5 death clustering may lead to strategies aimed at improving child health (Saha and Soest 20II). Kuate-Defo and Diallo (2002) stressed that the presence of death clustering may indicate marked inequality in terms of social amenities, distribution of resources in terms of hygiene, educational and health infrastructures and, may be indicative of poor sanitary and nutritional behaviour at the household or family level that are detrimental to the health and survival of children. While most of the existing research on under- 5 mortality clustering has been conducted in few countries such as Ghana (Adjuik et al. 2010; Awini et al. 20l0; van Bodegom et al. 20I2), South Africa (Sartorius et al. 20I0), and Tanzania (Lutambi et al. 2010), there is dearth of research on under-5 mortality clustering in Nigeria. We bridge this gap by examining the levels and factors influencing under- 5 mortality clustering in northern Nigeria using data collected from 20II to 2013 from the Nahuche Health and Demographic Surveillance System (HDSS) in Zamfara State.

\section{Data and Research Methods Study Setting}

The Nahuche HDSS consists of six districts of Bella, Gada, Karakai, Nahuche Keku, Nahuche Ubandawaki, and Rawayya in Bungudu LGA of Zamfara State. The site tracks changes in terms of health and demographic events in a geographically defined area with a surveillance population of 142, I 27 as of December 2013. The Nahuche HDSS started as collaboration between the Partnership for Reviving Routine Immunization in Northern Nigeria; Maternal, Newborn and Child Health (PRRINN$\mathrm{MNCH}$ ) Programme and Zamfara State Ministry of Health with funding from UKaid (United Kingdom Department for International Development) and the Norwegian Government in 2009. The site was set up to implement and evaluate the impact of interventions aimed at improving maternal and child health and promoting evidenced-based $\mathrm{MNCH}$ policy in Zamfara State in particular and north-western Nigeria in general (Doctor et al. 20I2). The social amenities within the surveillance area are deficient and typical of rural northern communities. For example, most communities lack power supply, access to improved water supply, and have poor road network. Economic and health indicators are also poor, with at least $75 \%$ of births occurring at home without a skilled birth attendant (Doctor et al. 20I I).

\section{Data and Methods}

We used fertility and mortality data from the Nahuche HDSS which, among others, are collected bi-annually to update the database. Prior to the update rounds of data collection, a baseline census was conducted in 2010 to establish the surveillance area population and its characteristics. The description of the data collection processes at Nahuche HDSS has been reported elsewhere (Alabi et al. 20/4). For this study, the focus was on mortality and fertility for all children under 5 years. Due to the living pattern in northern Nigeria, a compound with at least one under-5 death was the unit of analysis. Mortality and fertility data were disaggregated by year and for each year, compounds were grouped by the number of under- 5 births and deaths.

Factors influencing under-5 mortality clustering were explored using Sastry (1997) theoretical framework. Following Mosley and Chen (1984) framework for analysing determinants of child mortality in developing countries, Sastry divided these determinants into three main categories: Genetic, behavioural, and environmental; and opined that these determinants operates through child, family and community levels to influence child mortality. The main argument of Sastry's framework is that children from the same family are exposed to the same situation while children from the same community are also exposed to the same community conditions (Adedini 20l4a).

At the individual level, two groups of variables were explored: (I) child-level variables such as child's age 
and sex were explored for their role in predicting under-5 mortality clustering; and (2) mother's age, children ever born (CEB), parity in the 5 years before data collection, and health-seeking behaviour for sick children were explored as determinants of under-5 mortality clustering. At the compound level, family or compound wealth index and compound's source of drinking water were examined as predictors of under-5 mortality clustering. The wealth index was computed using Principal Component Analysis based on information on household characteristics which is usually updated once a year. This information include source of drinking water; type of toilet; whether toilet facilities are shared; material of main floor, walls, and roof; type of cooking fuel; access to electricity; household possessions such as television; radio; watch; motor vehicles; ownership of agricultural land; type and number of livestock owned. The household characteristics data for each of the households in a compound was aggregated to derive a compound characteristics data through a common identifier (compound ID) in the data. In Nahuche HDSS, a compound is a dwelling unit housing one or more households (which are generally not well defined) consisting of people who are blood relations. An individual is generally recognized as the head of the compound and virtually all issues affecting the affairs of all members including health-seeking decision are referred to the head.

The intervening variables for this study include uptake and quality of antenatal care (ANC) service and place of delivery of the most recent birth. These variables were examined as determinants of under-5 mortality clustering (outcome variable). The outcome variable was generated by aggregating the annual number of under-5 death by compound size (CEB) and applying binomial model which assesses the extent of child mortality clustering as the difference between the observed and the expected number of women with child death (Pradhan and Arokiasamy 2005). The excess of the 'expected' over the 'observed' number of women with under-5 death indicates clustering. Thus, six models were generated from the multivariate analyses. These models were fitted using Poisson regression model to predict determinants of under- 5 mortality clustering. Poisson regression model relates a count response variable to one or more predictors. The models are specified as follows:

Model I: Considered only the child's level factors on incidence rate of under-5 mortality clustering in order to examine the independent effect of child level factors.

http://aps.journals.ac.za
Model 2: This model (A) explained the effect of the individual level factors (mother and child level factors) on incidence rate of under-5 mortality clustering.

Model 3: Considered both the individual level factors and the intervening factors on incidence rate of under-5 mortality clustering.

Model 4: Considered the effect of compound level variables (compound wealth index and source of drinking water) in the multivariate analysis independent of other factors.

Model 5: Model 5 (B) incorporated compound and intervening variables into the multivariate analysis.

Model 6: Model 6 (C) incorporated the effects of individual, compound and intervening variables into the analysis

The Poisson model used the Incidence Rate Ratio (IRR) to explain the effect of explanatory variables on the outcome variable using the six models explained above. It is a ratio based on the rate or incidence of counts.

\section{Results}

Patterns of under-5 mortality clustering, 20II2013

A total of 4, 153 under- 5 deaths were reported from $201 \mathrm{I}$ to 2013 and the summary of the clustering is summarized in Tables I through 3 which show the number of compounds according to the number of CEB and number of under- 5 deaths. The analysis was done at the compound level to account for the living pattern of a typical rural northern Nigeria setting.

Table I shows that $73 \%$ of all compounds did not experience under-5 death in in 201I while one in every 5 compound experienced one under- 5 death. There were 970 compounds with two births and $71 \%$ (684 of 970 ) compounds had no under-5 death. Generally, $5 \%$ of the compounds had two or more under-5 deaths accounting for $35 \%$ of the total under- 5 deaths; and $22 \%$ of the compounds had one under- 5 death each thereby accounted for $65 \%$ of the under-5 deaths.

In Table 2 results show that in 20I2, less than $6 \%$ of the compounds accounted for $37 \%$ of the under- 5 mortality and these compounds had at least two under- 5 deaths. Twenty percent of the compounds accounted for almost two-thirds of the total under-5 deaths. Generally, $72 \%$ of compounds reported no under-5 death in 2012 . Using under-5 mortality rate of 224.8 per 1,000 live births (reported by Doctor and Abdulazeez 20I2), there were 958 compounds with two births of which $660(68.9 \%)$ reported no under-5 death in 2012. Thus, the survival chance of both children is given by $((1-0.2248) \wedge 2)$, which is $60 \%$. This implies that there were more compounds with no under-5 deaths than normally should be expected. It means that under-5 deaths happened in 
a number of compounds that is lower than could be expected. Alternatively, it was observed that $72 \%$ (Table 2) of all compounds in 2012 did not experience under-5 mortality. The average CEB in the study area was 4.8 thus, the expected percent of compounds that did not experience under-5 death is $((I-0.2248) \wedge 4.8)$, which is $29.5 \%$.
In 2013 (Table 3), there was a reduction in the percentage of compounds with no under- 5 death (65\%) from the $20 \mathrm{II}$ and 2012 figure $(73 \%$ and $72 \%$, respectively). The percentage of compounds with two or more deaths increased to $6.1 \%$ from $5.1 \%$ and $5.7 \%$ for $20 \mathrm{II}$ and $20 \mathrm{I}$, respectively.

Table I: Patterns of under-5 mortality clustering, Nahuche HDSS, 20I I

\begin{tabular}{|c|c|c|c|c|c|c|c|c|c|c|}
\hline \multirow[b]{2}{*}{$\begin{array}{l}\text { Births in } \\
\text { comp }\end{array}$} & \multicolumn{10}{|c|}{ Under-5 deaths in comp } \\
\hline & 0 & I & 2 & 3 & 4 & 5 & 6 & 7 & $\begin{array}{l}\text { Total } \\
\text { comp }\end{array}$ & $\%$ comp \\
\hline 1 & $173 \mid$ & 430 & & & & & & & 2161 & 57.1 \\
\hline 2 & 684 & 207 & 79 & & & & & & 970 & 25.6 \\
\hline 3 & 208 & 103 & 35 & 8 & & & & & 354 & 9.4 \\
\hline 4 & 75 & 46 & 20 & 4 & 5 & & & & 150 & 4.0 \\
\hline 5 & 35 & 19 & 8 & 3 & 0 & 1 & & & 66 & 1.7 \\
\hline 6 & 19 & 9 & 5 & 2 & 1 & 0 & 2 & & 38 & 1.0 \\
\hline 7 & 6 & 8 & 2 & 4 & 2 & 0 & 0 & 0 & 22 & 0.6 \\
\hline 8 & 1 & 2 & 1 & I & 0 & 2 & 0 & 0 & 7 & 0.2 \\
\hline 9 & 4 & I & I & 0 & I & 0 & 0 & 0 & 7 & 0.2 \\
\hline 10 & I & 0 & I & 0 & 0 & 0 & 0 & 0 & 2 & 0.1 \\
\hline II & 0 & 0 & 0 & I & 0 & 0 & 0 & 2 & 3 & 0.1 \\
\hline 12 & 0 & 0 & I & 0 & 0 & 0 & 0 & 0 & 1 & 0.03 \\
\hline 13 & 0 & I & 0 & 0 & 0 & 0 & 0 & 0 & I & 0.03 \\
\hline 17 & I & 0 & 0 & 0 & 0 & 0 & 0 & 0 & I & 0.03 \\
\hline \multicolumn{11}{|l|}{ Total } \\
\hline comp & 2765 & 826 & 153 & 23 & 9 & 3 & 2 & 2 & 3783 & 100.0 \\
\hline$\%$ comp & 73.1 & 21.8 & 4.0 & 0.6 & 0.2 & 0.1 & 0.1 & 0.1 & 100.0 & \\
\hline \% Death & 0 & 64.6 & 23.9 & 5.4 & 2.8 & 1.2 & 0.9 & 1.1 & 100.0 & \\
\hline
\end{tabular}

Note: comp $=$ compound

Table 2: Patterns of under-5 mortality clustering, Nahuche HDSS, 2012

\begin{tabular}{|c|c|c|c|c|c|c|c|c|c|c|c|c|c|}
\hline \multirow{2}{*}{$\begin{array}{l}\text { Births in } \\
\text { comp. }\end{array}$} & \multicolumn{13}{|c|}{ Under-5 deaths in comp. } \\
\hline & 0 & 1 & 2 & 3 & 4 & 5 & 6 & 7 & 8 & 9 & 10 & $\begin{array}{l}\text { Total } \\
\text { comp }\end{array}$ & $\begin{array}{l}\% \\
\text { comp }\end{array}$ \\
\hline I & 1847 & 495 & & & & & & & & & & 2342 & 57.9 \\
\hline 2 & 660 & 206 & 92 & & & & & & & & & 958 & 23.7 \\
\hline 3 & 250 & 99 & 40 & 14 & & & & & & & & 403 & 10.0 \\
\hline 4 & 86 & 45 & 25 & 7 & 2 & & & & & & & 165 & 4.1 \\
\hline 5 & 38 & 27 & I I & 4 & 0 & I & & & & & & 81 & 2.0 \\
\hline 6 & 17 & 20 & 10 & 4 & 1 & 1 & 0 & & & & & 53 & 1.3 \\
\hline 7 & 7 & 7 & 3 & I & I & 2 & 0 & 0 & & & & 21 & 0.5 \\
\hline 8 & 2 & 4 & 0 & 2 & 0 & 0 & I & 0 & 0 & & & 9 & 0.2 \\
\hline 9 & 0 & I & 2 & 0 & 1 & 0 & 1 & 0 & 0 & 0 & & 5 & 0.1 \\
\hline 10 & 0 & 2 & 2 & 2 & 0 & 0 & 1 & 0 & 0 & 0 & 0 & 7 & 0.2 \\
\hline II & 1 & 0 & 0 & 0 & 0 & 0 & 0 & 0 & 0 & 0 & 0 & I & 0.0 \\
\hline 13 & 0 & I & 0 & 0 & 0 & 0 & 0 & 0 & 0 & 0 & I & 2 & 0.0 \\
\hline Total comp & 2908 & 907 & 185 & 34 & 5 & 4 & 3 & 0 & 0 & 0 & 1 & 4047 & 100.0 \\
\hline$\%$ comp & 71.9 & 22.4 & 4.6 & 0.5 & 0.1 & 0.1 & 0.1 & 0 & 0 & 0 & 0 & 100.0 & \\
\hline$\%$ death & 0 & 62.7 & 25.6 & 7.1 & 1.4 & 1.4 & 1.2 & 0 & 0 & 0 & 0.7 & 100.0 & \\
\hline
\end{tabular}

Note: comp = compound 
Table 3: Patterns of under-5 mortality clustering, Nahuche HDSS, 2013

\begin{tabular}{|c|c|c|c|c|c|c|c|c|c|c|c|}
\hline \multirow{2}{*}{$\begin{array}{l}\text { Births } \\
\text { in } \\
\text { comp }\end{array}$} & \multicolumn{11}{|c|}{ Under-5 deaths in comp. } \\
\hline & 0 & 1 & 2 & 3 & 4 & 5 & 6 & 7 & 8 & $\begin{array}{l}\text { Total } \\
\text { comp }\end{array}$ & $\begin{array}{l}\% \\
\text { comp }\end{array}$ \\
\hline 1 & 1413 & 692 & & & & & & & & 2105 & 63.8 \\
\hline 2 & 474 & $|4|$ & 114 & & & & & & & 729 & 22.1 \\
\hline 3 & 160 & 70 & 28 & 21 & & & & & & 279 & 8.5 \\
\hline 4 & 49 & 29 & 12 & 5 & 0 & & & & & 95 & 2.9 \\
\hline 5 & 27 & 16 & 8 & 3 & 3 & I & & & & 58 & 1.8 \\
\hline 6 & 6 & 7 & 3 & 2 & 0 & 0 & 0 & & & 18 & 0.5 \\
\hline 7 & I & 5 & I & I & I & 0 & 0 & 0 & & 9 & 0.3 \\
\hline 8 & 0 & 0 & 0 & 2 & 0 & 0 & 0 & 0 & I & 3 & 0.1 \\
\hline 9 & 0 & 4 & 0 & 0 & 0 & 0 & 0 & 0 & 0 & 4 & 0.1 \\
\hline 13 & 0 & I & 0 & 0 & 0 & 0 & 0 & 0 & 0 & I & 0.0 \\
\hline $\begin{array}{l}\text { Total } \\
\text { comp }\end{array}$ & 2130 & 965 & 166 & 34 & 4 & I & 0 & 0 & I & 3301 & 100.0 \\
\hline & 64.5 & 29.2 & 5.0 & 1.0 & 0.1 & 0.0 & 0.0 & 0.0 & 0.0 & 100.0 & \\
\hline $\begin{array}{l}\% \\
\text { death }\end{array}$ & 0.0 & 67.6 & 23.2 & 7.1 & I.I & 0.4 & 0.0 & 0.0 & 0.6 & 100.0 & \\
\hline
\end{tabular}

Note: comp $=$ compound

Factors influencing under-5 mortality clustering, Nahuche HDSS

This section presents the determinants of under- 5 mortality clustering in the study area. Women of child bearing age (15-49 years) were asked information about the number of births they had in the 5 years preceding the data collection. A total of 8,933 women gave birth to 12,892 under-5 children, an average of 1.4 children per woman. More than half of the women reported that their under-5 children were girls with almost $60 \%$ of children being girls. Out of the 8,933 women, $10 \%(n=917)$ reported that their children had died. About $42 \%$ of the women reported that their children were aged I-2 years and a similar percentage reported their children being 3-4 years.

Based on the identified gap of dearth of literature on under-5 mortality clustering in Nigeria, this study examined the determinants of under- 5 mortality clustering from individual (mother and child factors), intervening and compound (household and families) levels.

Table 4 presents the incidence rate ratio (IRR) of under-5 mortality clustering for each of the predictors. Six models explained earlier, were used to test the effect of each of the factors on under- 5 mortality clustering. Model I (child-level factors) shows that, incidence rate of under- 5 mortality clustering reduced with increase in age. For example, children aged I-2 years had I4\% significantly lower mortality clustering incidence rate than infants while those aged 3-4 years had $22 \%$ significantly lower mortality clustering incidence rate than infants $(p<0.00 \mathrm{I})$. Female children had significantly higher mortality clustering incidence rate relative to male $(p<0.001)$.

Individual-level factors were examined in Model 2, Table 4. There was no statistically significant relationship between mother's age and mortality clustering. In terms of parity in the 5 years before the survey, the more the number of births, the higher the incidence rate of under-5 mortality clustering. For example, under- 5 children of women with 3-4 births in the 5 years before data collection had statistically significant higher rate of under-5 mortality clustering relative to women with $1-2$ births $(p<0.05)$. Seeking health care at health post or clinic significantly predispose to higher rate of under-5 mortality clustering.

Model 3 combined the individual-level factors (child and mother-level) with the intervening variables to examine its effect on incidence rate of under-5 death clustering. The effect of child's age on incidence rate of under-5 mortality clustering remains statistically significant. For example, under-5 children aged $3-4$ years had $32 \%$ significantly lower incidence rate of mortality clustering than infants $(p<0.001$, Model 3). Further, under-5 children who were delivered with the assistance of relatives had significantly higher incidence rate of mortality clustering in the study area $(p<0.05)$. 
Table 4: Poisson model explaining the effect of individual-level factors on under-5 mortality clustering

\begin{tabular}{|c|c|c|c|c|c|c|}
\hline & Model I & $95 \% \mathrm{Cl}$ & Model 2 & $95 \% \mathrm{Cl}$ & Model 3 & $95 \% \mathrm{Cl}$ \\
\hline Characteristics & $\begin{array}{l}\text { Child-level } \\
\text { variables } \\
\text { (IRR) }\end{array}$ & & $\begin{array}{l}\text { Individual- } \\
\text { level variables } \\
\text { (IRR) }\end{array}$ & & $\begin{array}{l}\text { (Individual } \\
\text { Intervening) } \\
\text { IRR }\end{array}$ & \\
\hline Child's age(years) & & & & & & \\
\hline Under I year & 1 & {$[1, I]$} & 1 & {$[1, I]$} & 1 & {$[\mathrm{I}, \mathrm{l}]$} \\
\hline |-2 years & $0.86 * *$ & {$[0.84,0.89]$} & $0.85^{* *}$ & {$[0.81,0.90]$} & $0.73^{* *}$ & {$[0.64,0.84]$} \\
\hline $\begin{array}{l}3-4 \text { years } \\
\text { Child's sex }\end{array}$ & $0.78 * *$ & {$[0.76,0.80]$} & $0.77 * *$ & {$[0.74,0.80]$} & $0.68 * *$ & {$[0.60,0.77]$} \\
\hline Boy & I & {$[\mathrm{I}, \mathrm{I}]$} & I & {$[1,1]$} & I & {$[\mathrm{I}, \mathrm{I}]$} \\
\hline Girl & $1.08^{* *}$ & {$[1.06,1.09]$} & $1.08^{* * *}$ & {$[1.04,1.13]$} & 1.04 & {$[0.92,1.17]$} \\
\hline Mother's age(years) & & & & & & \\
\hline $15-24$ & & & I & {$[1, I]$} & I & {$[1,1]$} \\
\hline $25-34$ & & & 1.01 & {$[0.96,1.06]$} & 1.09 & {$[0.94,1.28]$} \\
\hline $35+$ & & & 0.99 & {$[0.93,1.07]$} & 0.96 & {$[0.80,1.16]$} \\
\hline $\begin{array}{l}\text { Births in the last } 5 \\
\text { years }\end{array}$ & & & & & & \\
\hline $\mid-2$ & & & 1 & {$[1, I]$} & I & {$[1,1]$} \\
\hline $3-4$ & & & $1.09 *$ & {$[1.01,1.18]$} & 0.96 & {$[0.87,1.07]$} \\
\hline Children ever born & & & & & & \\
\hline 3 or less & & & 1 & {$[\mathrm{I}, \mathrm{I}]$} & I & {$[1,1]$} \\
\hline $4-6$ & & & 1.03 & {$[0.97,1.08]$} & 1.03 & {$[0.90,1.18]$} \\
\hline 7 & & & 0.99 & {$[0.93,1.07]$} & 0.91 & {$[0.78,1.07]$} \\
\hline $\begin{array}{l}\text { Health care } \\
\text { provider for last } \\
\text { child during illness }\end{array}$ & & & & & & \\
\hline No one & & & 1 & {$[\mathrm{I}, \mathrm{I}]$} & 1 & {$[\mathrm{I}, \mathrm{I}]$} \\
\hline Relatives & & & 0.98 & {$[0.94,1.03]$} & 0.96 & {$[0.84,1.1 \mathrm{I}]$} \\
\hline Local healer & & & 1.07 & {$[0.95,1.21]$} & 0.99 & {$[0.87,1.12]$} \\
\hline $\begin{array}{l}\text { CHEW in } \\
\text { community }\end{array}$ & & & & & & \\
\hline $\begin{array}{l}\text { community } \\
\text { Health post/clinic }\end{array}$ & & & $\begin{array}{l}1.02 \\
1.08^{*}\end{array}$ & $\begin{array}{l}{[0.98,1.07]} \\
{[1.02,1.14]}\end{array}$ & $\begin{array}{l}1.03 \\
1.03\end{array}$ & $\begin{array}{l}{[0.90,1.18]} \\
{[0.89,1.19]}\end{array}$ \\
\hline ANC Provider & & & & & & \\
\hline Doctor & & & & & I & {$[\mathrm{I}, \mathrm{I}]$} \\
\hline Nurse/Midwife & & & & & 1.04 & {$[0.79,1.35]$} \\
\hline $\mathrm{CHEW}$ in & & & & & & \\
\hline community & & & & & 0.92 & {$[0.69,1.24]$} \\
\hline TBA & & & & & 0.88 & {$[0.64,1.22]$} \\
\hline Others & & & & & 1.06 & {$[0.79,1.44]$} \\
\hline Place of child birth & & & & & & \\
\hline Home & & & & & I & {$[1, I]$} \\
\hline Health facility & & & & & 0.89 & {$[0.74,1.07]$} \\
\hline $\begin{array}{l}\text { Who assisted in the } \\
\text { delivery }\end{array}$ & & & & & & \\
\hline Skilled personnel & & & & & I & {$[1,1]$} \\
\hline TBA & & & & & 1.18 & {$[0.98,1.42]$} \\
\hline Relatives & & & & & $1.27^{*}$ & {$[1.07,1.52]$} \\
\hline Alone & & & & & 1.22 & {$[0.94,1.58]$} \\
\hline
\end{tabular}

Notes: ANC - Antenatal care; TBA - Traditional Birth Attendant; CHEW - Community Health Extension Worker

Relationship between compound, intervening variables and under-5 mortality clustering.

The effects of compound-level variables were examined in Model 4 in Table 5. The effect of compound's wealth status on incidence rate of under-5 mortality clustering was $5 \%$ significantly lower for under-5 children from compounds in the "middle" wealth status than their counterparts from the "poor" compounds. The incidence rate of under5 mortality clustering in the study area was not different between the middle and the rich compounds $(p<0.05)$. Furthermore, children from compounds which used open wells, water vendors and surface water as the source of drinking water had a higher incidence rate of mortality clustering than 
children from compounds with access to piped water as their main source of drinking water.

Model 5 (Table 5) examined the effects of compound and intervening variables on incidence rate of under- 5 mortality clustering. The results showed a statistically significant reduced incidence rate of mortality clustering among under-5 children from compounds in the "middle" wealth status after accounting for the effect of the intervening variables. Further, the results showed a significantly higher incidence rate of under5 mortality clustering for children from compounds with open well and water vendor as the main source of drinking water relative to children from compounds with piped water. Children who were delivered with the assistance of relatives showed a significantly higher incidence rate of under- 5 mortality clustering compared to being delivered by skilled personnel.

Table 5: Poisson model explaining the effects of compound-level and intervening factors on under-5 mortality clustering.

\begin{tabular}{|c|c|c|c|c|}
\hline \multirow[t]{2}{*}{ Characteristics } & Model 4 & $95 \% \mathrm{Cl}$ & Model 5 & $95 \% \mathrm{Cl}$ \\
\hline & \multicolumn{2}{|l|}{$\begin{array}{l}\text { Compound-level } \\
\text { variable (IRR) }\end{array}$} & \multicolumn{2}{|l|}{$\begin{array}{l}\text { Compound } \\
\text { Intervening } \\
\text { variables (IRR) }\end{array}$} \\
\hline \multicolumn{5}{|l|}{ Wealth index } \\
\hline Poor (r) & - & - & - & - \\
\hline Middle & $0.95 * *$ & {$[0.93,0.97]$} & $0.86^{*}$ & {$[0.77,0.96]$} \\
\hline Rich & $0.96 * *$ & {$[0.94,0.98]$} & 0.89 & {$[0.78,1.01]$} \\
\hline \multicolumn{5}{|l|}{$\begin{array}{l}\text { Source of drinking } \\
\text { water }\end{array}$} \\
\hline Piped water $(r)$ & - & - & - & - \\
\hline Open well & I.II* & {$[1.01,1.22]$} & I.09* & {$[1.01,1.19]$} \\
\hline Water vendor & $1.17^{*}$ & {$[1.05,1.29]$} & $1.15^{*}$ & {$[1.01,1.29]$} \\
\hline \multicolumn{5}{|l|}{ Covered } \\
\hline well/Borehole & 1.09 & {$[0.99,1.20]$} & 1.07 & {$[0.98,1.18]$} \\
\hline Surface water & $1.13^{*}$ & {$[1.03,1.24]$} & 1.11 & {$[0.98,1.28]$} \\
\hline $\begin{array}{l}\text { Rain water } \\
\text { ANC Providers }\end{array}$ & 0.98 & {$[0.89,1.08]$} & - & - \\
\hline Doctor $(r)$ & & & - & - \\
\hline Nurse/Midwife & & & 0.90 & {$[0.79,1.02]$} \\
\hline \multicolumn{5}{|l|}{ CHEW in } \\
\hline community & & & 0.89 & {$[0.77,1.04]$} \\
\hline TBA & & & 0.92 & {$[0.75,1.13]$} \\
\hline Others & & & 0.95 & {$[0.79,1.15]$} \\
\hline \multicolumn{5}{|l|}{ Place of child birth } \\
\hline Home (r) & & & - & - \\
\hline Health facility & & & 1.05 & {$[0.91,1.21]$} \\
\hline \multicolumn{5}{|l|}{$\begin{array}{l}\text { Who assisted in the } \\
\text { delivery }\end{array}$} \\
\hline Skilled personnel $(r)$ & & & - & - \\
\hline TBA & & & 1.06 & {$[0.95,1.18]$} \\
\hline Relatives & & & $1.12^{*}$ & {$[1.00,1.25]$} \\
\hline Alone & & & 1.12 & {$[0.97,1.23]$} \\
\hline
\end{tabular}

Notes: $r$ - reference category. ANC - Antenatal care; TBA - Traditional Birth Attendant; CHEW - Community Health Extension Worker

Adjusted effects of individual, and compound factors on under-5 mortality clustering

Model 6 (Full model in Table 6) assesses the effect of all the individual, compound and intervening levels variables on under-5 mortality clustering. Results showed that child's age significantly predicts incidence of under-5 mortality clustering. Older children had a reduced IRR relative to infants. Furthermore, sourcing drinking water from surface water (spring, river/stream, pond, and dam) significantly increased the incidence rate of under-5 mortality clustering in the study area. Deliveries assisted by "relatives" significantly increased the incidence rate of under-5 mortality clustering $(p<0.05)$. Estimates for some categories of "source of drinking water" were not computed due to limited number of cases. 
Table 6: Poisson model explaining the effects individual, compound and intervening levels factors on under-5 mortality clustering.

\begin{tabular}{|c|c|c|}
\hline \multirow[b]{2}{*}{ Characteristics } & Model 6 & \multirow[b]{2}{*}{$95 \% \mathrm{Cl}$} \\
\hline & $\begin{array}{l}\text { (Individual + } \begin{array}{l}\text { Compound } \quad+ \\
\text { Intervening variables) IRR }\end{array} \\
\end{array}$ & \\
\hline \multicolumn{3}{|l|}{ Child's age(years) } \\
\hline Under I year & I & {$[1, I]$} \\
\hline |-2 years & $0.75 * *$ & {$[0.66,0.87]$} \\
\hline $3-4$ years & $0.71 * *$ & {$[0.63,0.80]$} \\
\hline \multicolumn{3}{|l|}{ Child's sex } \\
\hline Boy & 1 & {$[1,1]$} \\
\hline Girl & 1.02 & {$[0.91,1.13]$} \\
\hline \multicolumn{3}{|l|}{ Mother's age(years) } \\
\hline $15-24$ & I & {$[1,1]$} \\
\hline $25-34$ & 1.08 & {$[0.93,1.27]$} \\
\hline $35+$ & 0.95 & {$[0.78,1.16]$} \\
\hline \multicolumn{3}{|l|}{ Births in the last 5 years } \\
\hline $1-2$ & I & {$[1,1]$} \\
\hline 3-4 & 0.99 & {$[0.89,1.11]$} \\
\hline \multicolumn{3}{|l|}{ Children ever born } \\
\hline 3 or less & I & {$[1,1]$} \\
\hline $4-6$ & 1.05 & {$[0.92,1.19]$} \\
\hline 7 & 0.91 & {$[0.78,1.07]$} \\
\hline \multicolumn{3}{|c|}{$\begin{array}{l}\text { Health care provider for last ill child } \\
\text { during illness }\end{array}$} \\
\hline No one & 1 & {$[1,1]$} \\
\hline Relatives & 1.01 & {$[0.88,1.15]$} \\
\hline Local healer & 1.13 & {$[0.86,1.48]$} \\
\hline CHEW in community & 1.14 & {$[0.95,1.35]$} \\
\hline Health post/clinic & 1.14 & {$[0.96,1.36]$} \\
\hline \multicolumn{3}{|l|}{ Wealth Status } \\
\hline Poor & I & {$[1, I]$} \\
\hline Middle & 1.08 & {$[0.92,1.26]$} \\
\hline Rich & 1.07 & {$[0.89,1.29]$} \\
\hline \multicolumn{3}{|l|}{ Source of drinking water } \\
\hline Piped water & I & {$[1,1]$} \\
\hline Open well & - & - \\
\hline Water vendor & 0.95 & {$[0.75,1.21]$} \\
\hline Covered well/Borehole & 1.03 & {$[0.91,1.18]$} \\
\hline Surface water & $1.33 *$ & {$[1.13,1.57]$} \\
\hline Rain water & - & - \\
\hline \multicolumn{3}{|l|}{ ANC provider } \\
\hline Doctor & 1 & {$[1,1]$} \\
\hline Nurse/Midwife & 0.96 & {$[0.75,1.22]$} \\
\hline $\mathrm{CHEW}$ in community & 0.89 & {$[0.67,1.17]$} \\
\hline TBA & 0.81 & {$[0.59,1.11]$} \\
\hline Others & 1.08 & {$[0.75,1.55]$} \\
\hline \multicolumn{3}{|l|}{ Place of child birth } \\
\hline Home & I & {$[1,1]$} \\
\hline Health facility & 0.89 & {$[0.73,1.09]$} \\
\hline \multicolumn{3}{|c|}{ Who assisted in the delivery } \\
\hline Skilled personnel & 1 & {$[1,1]$} \\
\hline TBA & 1.12 & {$[0.93,1.36]$} \\
\hline Relatives & $1.19 *$ & {$[1.00,1.42]$} \\
\hline Alone & 1.14 & {$[0.89,1.45]$} \\
\hline
\end{tabular}

\section{Discussion}

In this analysis we identified patterns of under-5 mortality clustering from $201 \mathrm{I}$ to 2013 and explored the individual and compound levels factors influencing under-5 mortality clustering using data from Nahuche HDSS in Zamfara State, northern Nigeria. We found that under-5 mortality clustered among some women and compounds over the study period. Results also 
showed that under-5 mortality occurred in $28 \%$ of the compounds rather than in the expected $70 \%$ of the compounds. The finding is in line with a similar study on infant mortality clustering (Vandezande et al 2010) which found that more families reported no child deaths than was expected.

Trend analysis shows that the difference between the expected percentages of families/compounds with no under-5 deaths reduced from $42 \%$ in 201 I to $41 \%$ in 2012 and $32 \%$ in 2013 . This trend could partly be explained by various intervention programmes deployed in the study areas by development partners such as the nutrition programme "Working to Improve Nutrition in Northern Nigeria (WINNN)" The WINNN Programme aims to enhance nutritional status of II million children under-5 years old through delivery of nutrition interventions under the routine health services in five Northern States (Jigawa, Zamfara, Kebbi, Katsina, and Yobe). The WINNN Programme is a six-year (20II-20I7) collaboration of the Department for International Development (UKAid), The Nigeria Federal Ministry of Health, Save the Children International, Action Against Hunger, and UNICEF (UNICEF 20I5). The WINNN Programme implemented critical and effective interventions to improve under- 5 mortality by providing treatment of malnutrition, including community-based management of acute malnutrition, vitamin A supplementation and deworming, and promotion of infant and young child feeding (Liu et al 20I5).

Working in four northern Nigeria States (including Zamfara State), the PRRINN-MNCH Programme deployed interventions in communities that focused on promoting Universal Health Coverage. These interventions aimed at promoting equal access for remote, rural populations through Community-Based Service Delivery; addressing delays in Emergency Obstetric Care; highlighting the clustering of morbidity and mortality to effect changes in services and community responses; and ensuring standing permission for mothers and children to access health services. Since its inception in 2009, estimates suggest that the PRRINN-MNCH Programme contributed to saving 22,000 women, 50,000 infants and 100,000 children across the four states. In immunization coverage, the programme also contributed to a sevenfold increase in fully immunized children, of which approximately half is firmly programme attributable. End of PRRINN$\mathrm{MNCH}$ Programme results showed that these interventions were associated with nearly $50 \%$ reduction in under-5 mortality rates: from 160 per 1,000 live births during the programme baseline in 2009 to 95 per I,000 live births by 2013 (PRRINN$\mathrm{MNCH}$ Programme 2013). Our findings also confirm the impact of various interventions aimed at reducing child and maternal deaths as evidenced by the percent of families reporting under- 5 deaths from $20 \mathrm{II}$ to $20 \mathrm{I} 3$ and the associated measures of under-5 mortality clustering. These findings underscores the importance of and urgent need for the interventions that are evidence-based and that focus on improved quality and availability of health services including antenatal and postnatal care, safer deliveries, care for newborns and infants, better nutrition, and routine immunization against preventable diseases. Our finding are also aligned with various studies (Klouda and Adamu 2013; Sastry 1997; Vandezande et al. 2010) on infant and child mortality clustering which stressed that the burden of under- 5 mortality is on few families/compounds and thus called for interventions targeting the few families/compounds.

The observed lower incidence rate of under- 5 mortality clustering among older age groups of under-5 relative to infants is consistent with findings from other studies on mortality clustering (e.g. Sastry 1997); where the risk of dying decreased steadily with child's age. Consistent with Adedini (20l4b), we also found that the incidence of under-5 mortality clustering was higher among mothers who gave birth at a young age than those who gave birth at older ages. This may probably be due to the prevalence of early marriage and early childbearing in the study area. Compound-level variables showed a significant effect in determining under-5 mortality clustering; with clustering higher incidence rate among compounds with other source of drinking water such as surface water (streams, river) relative to under- 5 children in compounds with piped water. Adedini (20l4b) also found similar effect of source of drinking water on infant and child mortality. However, it was reported that after adjusting for other factors, the significance of the effects of household source of drinking water in predicting infant and child mortality reduced.

That adequate utilization of prenatal, delivery and postnatal care services influences under- 5 survival has been well documented elsewhere (e.g. Kayode et al. 20I4). A reduced likelihood of neonatal mortality was reported for women who used these services. For example, the incidence rate of under- 5 mortality clustering for deliveries assisted by relatives had a significantly higher incidence of under-5 mortality clustering relative to deliveries assisted by skilled personnel. The preponderance of births delivered with assistance of traditional birth attendants is associated with lower infant survival (Adedini et al. 2014c; Fapounda and Orobaton 2013; ). For example, Fapounda and Orobaton (2013) reported a $94 \%$ delivery rate with "no one present" in northern Nigeria. 
The MDGs in 2000 provided an opportunity for the international community to implement interventions and review policies to reduce under- 5 mortality by two-thirds by 2015, from the 1990 levels. A number of countries made drastic reductions while others had struggled to meet the deadlines. While the bulk of this mortality burden is in rural and disadvantaged areas, our results have shown that communities can register mortality reductions if they are exposed to effective and targeted interventions to improve child survival. The Sustainable Development Goals (SDGs) provide another opportunity to consolidate efforts to "ensure healthy lives and promote well-being for all at all ages" (SDG 3). In particular, one of the SDG 3 targets is to end preventable deaths of newborns and children under-5 years of age by 2030 (United Nations 20I5a). To ensure healthy lives and promote well-being for all neonates goes beyond identifying the cost-effective interventions documented elsewhere (Khan et al. 20I3; Darmstadt et al. 2008)6 such as newborn resuscitation, breastfeeding, kangaroo mother care for low birth weight infants but ensuring massive scale-up of human resources as well and marshaling resources to make a rapid reduction in neonatal mortality (Cooper et al 2013).27 Nevertheless, the international calls to reduce preventable deaths and improve child survival towards by 2030 is an opportunity to revisit the strategies and commitment in Nigeria at all levels of governments. Pursuant to Africa "Agenda 2063" - a global strategy to optimize use of Africa's resources for the benefit of all Africans - policies that build on the successes and challenges of Africa's recent poverty reduction strategies as well as promoting equal distribution of resources are likely to lead Africa and Nigeria in particular toward the SDGs. Pursuing this will ensure that reductions in under- 5 mortality rates are significant by 2030 .

\section{Conclusion}

Analysis of data from Nahuche HDSS, among other things, showed that under-5 mortality clustering occurred within few families than expected within the surveillance area over the 3 year period (201 I20I3). Further, the difference between the expected and the actual number of families which did not experience under-5 mortality reduced from $20 \mathrm{II}$ to 2013 with 2013 having minimal differences compared with $201 \mathrm{I}$ and 20I2. This suggests the effect of evidence-based intervention in reducing the burden of under-5 mortality in the study area and calls for a sustained tempo in generating timely data to inform such interventions. Government policies informed by evidence-based findings from such research platform will help fast-track the process of reducing under-5 mortality in Nigeria.
Furthermore, individual-level factors such as child's age and intervening factors such as assistance at delivery have implications at reducing under-5 mortality clustering within the DSA in particular and northwest Nigeria in general. The incidence rate of under-5 mortality clustering in infancy is higher than during childhood. Improved neo-natal care and living standards have implication in reducing under-5 mortality clustering. This study, therefore, contributed to research by bridging the knowledge on under-5 mortality clustering in Nigeria.

\section{Consent and Ethical Approval}

Ethical clearance and informed consent was obtained for the demographic surveillance activities prior to the commencement of routine data collection activities from all the stakeholders involved and from the Zamfara State Ministry of Health Research Ethics Committee.

\section{Disclaimer}

The views expressed in this paper are those of the authors and do not represent the views of their organizations or institutions.

\section{References}

Adedini S.A. (2014a). Neighbourhood characteristics and under-five mortality in Nigeria. African Population Studies Vol 27, 2 Supp.

Adedini S.A. (20I4b). Contextual determinant of infant and child mortality in Nigeria. PhD held at the University of the Witwatersrand, Johannesburg, South Africa

Adedini S.A., Odimegwu C., Bamiwuye O., Fadeyibi O., \& De-Wet N. (20I4c). Barriers to accessing health care in Nigeria: implications for child survival. Global Health Action 7: 23499 doi.org//0.3402/gha.v7.23499

Adjuik M, Kanyomse E, Kondayire F, Wak G, \& Hodgson A. (20I0). Clustering of under-five mortality in the Navrongo HDSS in the KassenaNankana District of northern Ghana. Global health Action 30:3. doi: 10.3402/gha.v3i0.5233.

African Union Commission. 2014. Agenda 2063: The African we want. Addis Ababa: African Union Commission. Available at http://archive.au.int/assets/images/agenda2063.pdf (Accessed 22 January 2017).

Alabi O, Baloye D, Doctor HV. \& Oyedokun O. (2016). Spatial Analysis of Under-five Mortality Clustering in Northern Nigeria: Findings from Nahuche Health and Demographic Surveillance System, Zamfara State. IJTDH, I5(I): I-10, 2016. DOI: 10.9734/IJTDH/2016/24709

Alabi O \& Doctor H.V. (2015). The potential role of a health and demographic surveillance system in 
rural Northern Nigeria to reduce maternal and child deaths. Health, 7,174I| 746.doi: 10.4236/health.2015.7/2189.

Alabi O., Doctor H.V., AbdulAzeez Jumare, Nasiru Sahabi, Ahmad Abdulwahab, Sally E. Findley \& Sani D. Abubakar. (20|4) "Profile: The Nahuche Health and Demographic Surveillance SystemNorthern Nigeria [Nahuche HDSS]". International Journal of Epidemiology doi: 10.1093/ije/dyul 97

Awini E, Mattah P, Sankoh O, \& Gyapong M (20I0). Spatial variations in childhood mortalities at the Dodowa Health and Demographic Surveillance System site of the INDEPTH Network in Ghana. Trop Med Int Health.15(5):520-8. doi: 10.1III/j.1365-3|56.2010.02492.x. Epub 2010 Mar 15.

Cooper PA. (20/3). The challenge of reducing neonatal mortality in low- and middle-income countries. Pediatrics. 133: 5-6.

Darmstadt GL, Walker N, Lawn JE, Bhutta ZA, Haws RA, \& Cousens S.(2008). Saving newborn lives in Asia and Africa: cost and impact of phased scaleup of interventions within the continuum of care. Health Policy Plan; 23(2): I0I-I I 7.

Doctor H.V., Alabi O., Findley S.E., Afenyadu G.Y., Abdulwahab A, \& Jumare A. (20I2). Maternal mortality in northern Nigeria: findings of a health and demographic surveillance system in Zamfara State, Nigeria. Tropical Doctor 42: |40-| 43.

Doctor H.V. \& Abdulazeez J. (20I2). Nahuche Health and Demographic Surveillance System Selected Demographic Indicators: Results from the Household Registration System (version 2). Available from Nahuche HDSS office, Zamfara State.

Doctor H.V., Bairagi R, Findley S.E., Helleringer S, \& Dahiru T. (20II). Northern Nigeria Maternal, Newborn and Child Health Programme: Selected analyses from population-based baseline survey. Open journal of Demography 4: I I-2I.

Fapohunda B.M., \& Orobaton N.G. (20|3). When Women Deliver with No One Present in Nigeria: Who, What, Where and So What? PLoS ONE 8(7): e69569. doi:I0.137|/journal.pone.006956

Khan AA, Zahidie A, \& Rabbani F. (20/3). Interventions to reduce neonatal mortality from neonatal tetanus in low and middle-income countries - a systematic review. BMC Public Health. 13: 322

Kayode, G.A., Ansah E., Agyepong I.A., AmoakohColeman, M., Grobbee, D.E. \& KlipsteinGrobusch, K. (20|4). Individual and community determinants of neonatal mortality in Ghana: a multilevel analysis. BMC Pregnancy and Child Birth 14: |47|-2393 Retrieved from http://www.biomedcentral.com/ I 47 I -

2393/14/165

Klouda A.T. \& Adamu F. (20I3). Clustering of Child Mortality and Links to Social Support in Northern Nigeria. A report submitted to PRRINN-MNCH Programme. Available from www.prrinnmnch.org

Kuate-Defo B., \& Diallo K., (2002).Geography of Child Mortality Clustering within African Families. Health \& Place (8) 93-117

Lutambi AM, Alexander M, Charles J, Mahutanga C, \& Nathan R. (20I0). Under-five mortality: spatialtemporal clusters in Ifakara HDSS in Southeastern Tanzania. Global Health Action.30:3. doi: 10.3402/gha.v3i0.5254.

Mosley W.H. \& Chen L.C. (1984). An analytical framework for the study of child survival in developing countries, Population and Development Review 10 (Suppl.): 25-45.

NPC and ICF International (2014). Nigeria 2013 Demographic and Health Survey. Abuja, Nigeria, and Rockville, Maryland, USA: NPC and ICF International

Pradhan J \& Arokiasamy P. (2005). Individual and family level clustering of child mortality in Orissa. Retreived from: http://www. iussp2005.princeton.edu/paper/5 I 36I. (Accessed 17/03/2016)

PRRINN-MNCH Programme (2013). Final report 20/3. Stronger systems: healthy women and children. Kano, Kano State: PRRINN-MNCH Programme. Available at http://www.prrinnmnch.org/documents/PRRINN-

MNCHFinalReport2013.pdf (Accessed I8 January 20I7)

Saha U.R., \& Van Soest A (20II). Infant death clustering in families: Magnitude, causes, and the influence of better health services, Bangladesh 1982-2005. Population Studies, Vol. 65, No. 3, 273-287.

Sartorius B, Kahn K, Vounatsou P, Collinson M.A. \& Tollman S.M. (20I0). Space and time clustering of mortality in rural South Africa (Agincourt HDSS), 1992-2007. Available at http://www.globalhealthaction.net/index.php/gha/ article/view/5225 (Accessed 19/3/2016).

Sastry, N., (1997). Family-level clustering of childhood mortality risk in Northeast Brazil. Population Studies, 51 , 245-26.

UNICEF (2015). Eight bi-annual progress and utilization update to the United Kingdom Department for International Development. Abuja, Nigeria: UNICEF. Available at https://www.unicef.org/nigeria/DFID SCI 10476 8th_Biannual_Donor_Report-_Nutrition-Final.pdf (Accessed 18 January 2017). 
UNICEF (20I4). Levels and trends in child mortality. New York: UNICEF. Available at http://www.unicef.org/media/files/Levels_and_Tre nds_in_Child_Mortality_2014.pdf (Accessed 19/3/2016)

United Nations (2015). Transforming our world: the 2030 agenda for Sustainable Development. Resolution adopted by the General Assembly on 25 September 2015. New York: United Nations; 2015

Van Bodegom D., Eriksson U.K, HouwingDuistermaat J.J, \& Westendorp R.G. (20/2). Clustering of child mortality in a contemporary polygamous population in Africa. Biodemography Soc Biol. 58(2):162-72. doi: I0.1080/I9485565.20I2.720445
Vandezande M., Moreels, S., \& Matthijs, K., (20l0). Explaining death clustering: Intergenerational patterns in infant mortality Antwerp 1846-1905, Working paper of the Scientific Research Community Historical Demography, Centre for Sociological Research, Leuven. www.iussp2005.princeton.edu/papers/5 | $36 \mid$

You D., Hug L., Ejdemyr S., \& Beise J (20I5). Levels and Trends in Child mortality report: estimates developed by the UN Inter-agency Group for Child Mortality Estimation. Available at: https://data.unicef.org/wpcontent/uploads/2015//2/IGME-report-2015child-mortality-final_236.pdf.

(Accessed I/I I/2017) 